\title{
03
}

\section{WORDS MATTER: A SHARED BASELINE VOCABULARY}

\author{
Julie Mennes
}

\section{Finding the Right Words}

This volume is about challenges to and the enabling conditions of inter- and transdisciplinary (ITD) processes in urban research and practice. However, it is also a result of these processes: as illustrated in the framework Part I.2. The 16 stories in Parts II and III and analyses and discussions in Parts I and IV are the product of a collaboration between authors with backgrounds in different disciplines related to urban research and practice.

One of the four enabling conditions included in the Framework for inter- and transdisciplinary processes concerns the words that are used, their epistemic diversity and their potential for ambiguity. It stresses the importance of dedicating time and resources to the identification and exploration of differences in the meaning of key terms throughout any collaboration and the subsequent development of shared understanding. The experiences reported in this volume, as well as experiences from the production of this volume, suggest that existing scholarly definitions only constitute starting points for the creation of shared understanding in inter- and transdisciplinary processes (Nikulina et al., 2019; von Wehrden et al., 2018). Ideally, a shared baseline vocabulary is co-designed and coproduced, which also offers the space needed to enhance mutual understanding and learning; this is a theme further discussed in Chapter IV.3. In the process of producing this volume, an effort was made to create a baseline vocabulary in response to the ambiguity of key terms. This chapter presents the result of that effort. 


\section{Understanding Ambiguity}

In linguistics, a word is called "ambiguous" when it has multiple meanings (Klepousniotou, 2002). If these meanings have a shared etymological origin, they are polysemous; if they do not, they are homonymous (Tuggy, 1993). Ambiguity is a general phenomenon that occurs in everyday communication. In inter- and transdisciplinary communication settings, the jargon of the different disciplines and professions are an important source of ambiguity. Firstly, some words are part of the jargon of multiple disciplines, but have different meanings across those jargons (Eigenbrode et al., 2007). Secondly, some jargon has a common, non-specialised meaning in everyday language (Wear, 1999). Mere ambiguity does not pose a challenge for inter- and transdisciplinary communication. But, when the context in which an ambiguous word is used allows for different interpretations of the word, i.e. for different meanings to be ascribed to the word, the situation can become tricky. Interlocutors can then have the impression that they are talking about the same thing while this is not the case. However, even if interlocutors indeed ascribe different meanings to an ambiguous word, real problems only arise when two more conditions are met, firstly if the word plays a significant role in the conversation, i.e. its interpretation has an impact on the course of the conversation; and secondly if the different interpretations of the word contrast in a relevant way, i.e. the meaning that is ascribed by some interlocutors is excluded by others.

In the case of ambiguity across disciplinary jargons, the different meanings of a word can be closely related; they can be about the same phenomenon, but highlight different aspects in line with the central interest(s) of the respective disciplines or professions (Szostak, 2014). Jargon is interconnected with the methodological, epistemological and metaphysical assumptions underlying a discipline or profession. In cases where the different meanings are closely related, the second condition is better expressed in terms of excluded meaning components, rather than (full) meanings. When these conditions are met, an ambiguous word can trigger different problematic scenarios. In one scenario, the interlocutors (increasingly) struggle to understand each other, and this slows down their communication. In such a case, the interlocutors either become aware of the problem and try to resolve it, which requires the conversation to be paused until a resolution is found, or their communication breaks down entirely. In an alternative scenario, interlocutors are completely unaware of the miscommunication. In such a case, the word can cause huge misunderstandings, (the effects of) which are only noticed after a long time.

\section{The Process of Building a Baseline Vocabulary}

The challenges related to words and meanings were experienced first-hand in the process of cowriting this volume. Especially in the early stages, the meetings of the authors were slowed down more than once because of a lack of conceptual common ground, made worse due to diverse disciplinary backgrounds and multiple distinct "key" scholarly references. Whenever this situation occurred, the team of authors resolved it by using a three-step strategy. First, word(s) causing confusion were identified. Next, all meanings that were ascribed to the word had to be made explicit. Finally, a baseline definition was agreed upon, i.e. a definition that fixed the meaning that functions as the default one in the context of the collaboration, but that was not assumed to capture the one and only relevant meaning of the word. These baseline definitions were found to be an important enabler for interdisciplinary collaboration among the authors as they increased the efficiency of communication and strengthened the group identity. Therefore, it was decided to note the definitions down and to extend the list into a baseline vocabulary that would cover the key words of the volume. 
These key words were nominated by the authors of the case study chapters (in a group discussion) or selected by the author of the baseline vocabulary (based on an analysis of drafts of the case study chapters). For key words, baseline definitions were drafted based on a lexicographical study of the case study chapters. These drafts were then evaluated in a moderated group discussion and, based on the provided feedback, the definitions were adjusted and fine-tuned. In this way, it was ensured that the relevant (discipline- or practice-oriented) perspectives of the authors of the case study chapters would be integrated into the baseline vocabulary.

\section{Usage of the Baseline Vocabulary}

The baseline vocabulary is a tool that was used by the authors in the preparation of this volume, and can also be used by its readers. The usage by the authors was twofold. In the early stages of their collaboration, the baseline vocabulary was used to consolidate mutual understanding in the way described above. At a later stage, when chapters were being finalised, the vocabulary was used to maximise the terminological coherence of the volume: for every occurrence of a key word, the authors made sure that the meaning of the word accorded with its baseline definition, or that, where necessary, a deviation in use was clearly indicated and an alternative definition provided.

For readers, the baseline vocabulary forms an easy guide to the conceptual backbone of the volume. It allows them to quickly identify the key words and to understand their default meaning. The baseline vocabulary is an important tool, its visibility and accessibility increased by including it in Part I of the volume.

\section{The Structure of the Baseline Vocabulary}

The baseline vocabulary consists of entries (i.e. key words) and their baseline definition. When a baseline definition is based on existing definitions of the word, the necessary references are included. The entries are ordered alphabetically.

Actor

In the context of a project, actors, or agents, are the entities (e.g. people, institutions, organisations or companies) that make an active contribution to the implementation of the project. Actors can be members of or can be external to the team responsible for the project. In general, team members contribute to a project by introducing expert knowledge or technical skills and/or by managing and coordinating the project. External actors make requests or provide information and feedback to team members. Note that the involvement and role of actors may change in the course of a project.

\section{Agency}

In the context of working practices, it is defined as capacities for action. In urban activism, agency implies action, engagement and looking outwards. Involvement and acting in the context of research outside the academy is also about transformation, acting both within and between the fields of research, practice, education and civic life. It is often used in conjunction with alternative practices. 


\section{Case study}

A case study is a method for studying a phenomenon in a real-life context with the goal of illustrating or learning general principles. In this volume, the cases are (urban research and practice) projects and their study is guided by a framework of analysis that is focused on barriers and enablers for inter- and transdisciplinarity.

\section{Challenge}

A challenge, or "challenging condition," poses a hurdle for the (efficient) execution of a project. By making the necessary efforts, challenges can be overcome. When used in the context of cross-disciplinarity, the concept is implicitly comparative and refers to hurdles that are caused by characteristics that differentiate inter-, trans- or multidisciplinary projects from traditional, disciplinary projects. Examples of such characteristics are "combining knowledge from different disciplines" and "collaborating with stakeholders."

\section{Change agent}

Change agents are actors (individuals or organisations) who catalyse a transformative process within society. Often these individuals or organisations facilitate processes of co-producing knowledge and mediate between the many fields of interests and hierarchies.

\section{Civic - inspired by Putnam (1993)}

"Civic" indicates the involvement of citizens or communities, where this involvement can be active (i.e. citizens contributing to the realisation or maintenance of something) or passive (i.e. something that concerns citizens, cities and/or public affairs). Put differently, "civic" means that something is $b y$ citizens, or that it is for citizens. The combination of both meanings is also common.

\section{Co-design - based on Mauser et al. (2013); Polk (2015); Lang et al. (2012)}

Co-design is the first phase of an inter- or transdisciplinary project. It is the phase in which the goals of the project are determined. It comprises (i) defining the central questions or problems; (ii) deciding on (the nature of) the desired answers or solutions; and (iii) identifying the knowledge and/or skills required for the answers/solutions. Besides referring to a project phase, "co-design" also indicates that an inclusive approach is taken, i.e. an approach in which the input of all relevant actors and the interests of all stakeholders are taken into account.

\section{Collaboration}

When two or more people work together to create or achieve something as one, or to work jointly with others. Collaboration can include networks, coalitions, movements, strategic alliances. In successful collaboration the processes and methods for participating as well as the quality and degree of the participation result in in-depth contributions from both practice and research (Polk 2015). 


\section{Community}

A group of people who interact with each other because they live in the same area and/or have a similar interest or background. Some community types that are particularly relevant in the context of urban research and practice are characterised by a similar interest (e.g. a community of academic researchers), a similar profession (e.g. a community of practitioners), a similar occupation (e.g. a community of entrepreneurs), a similar living environment (e.g. a neighbourhood community) or involvement in a transdisciplinary project (e.g. a community of collaborators).

\section{Competence}

In general, competences are skills and abilities. In the framework for analysis, "competence" refers specifically to those skills that allow the facilitation of the process of inter- and transdisciplinary knowledge generation. Two important examples are "communication" and "leadership/management." The first includes both internal communication, i.e. among team members, and external communication, i.e. between team members and external actors and stakeholders. Leadership/management includes overseeing the project, making sure the timeline is respected, facilitating joint knowledge production and intervening in conflicts.

\section{Context}

The context of a project is the circumstances under which the project is started (and carried out). These circumstances can be societal, financial, cultural, social, institutional, etc. Some examples of circumstances are the reason(s) for starting the project; the amount and source of means available for the project; the research agenda or philosophy to which the project subscribes; the people who show interest in the project; the rules or habits of the actors involved.

\section{Continuation}

Once the goals of a project have been reached and/or the funding for the project has ended, it may be decided that the project is to be continued. This continuation may consist of the writing of a new project proposal aimed at expanding or deepening the original project, or the team members deciding to prolong (and diversify) their collaboration, or initiating an additional event inspired by and conducted in the frame of the project. In a broader sense, continuation refers to the drawing on the legacy of previous experiences.

\section{Co-production - based on Mauser et al. (2013); Polk (2015); Lang et al. (2012)}

Co-production is the phase of an inter- or transdisciplinary project in which answers to the central questions are generated, or solutions for the central problems are created. As with "co-design," the word "co-production" indicates that an inclusive approach is taken, i.e. one that maintains a dialogue between all relevant actors, and if applicable, stakeholders.

\section{Cross-disciplinarity - based on O'Rourke and Crowley (2013)}

All endeavours that involve multiple disciplines, at least one of which is academic. Different types of cross-disciplinarity are inter-, multi- and transdisciplinarity. 


\section{Decision-maker}

In general, decision-makers are the people who set the agenda of large organisations such as companies and unions, but also municipalities and state authorities. In the context of a research project, decision-makers are the entities (e.g. people, institutions, organisations or companies) that have the final word about the course of the project. Generally, they obtained their authority by having provided financial support to the project (e.g. in the case of business partners) and/or by being responsible for the result of the project (e.g. in the case of local governments).

\section{Discipline}

In a broad sense, "discipline" refers to any area of expertise. Typically, it is used to refer to an area of study as defined by the organisational structure of universities.

\section{Disposition - inspired by Bourdieu (1999)}

"Dispositions" refer to distinct capacities of individuals and/or groups to (re-)act, which, rather than being trained or consciously learnt, are shaped through social experience in different fields of human conduct. Dispositions play a significant role in inter- and transdisciplinary processes, especially when it comes to facilitating stages in the co-design and co-production of knowledge.

\section{Dissemination}

Dissemination is the last phase of a project. It is the phase in which the acquired knowledge or solution is implemented and shared.

\section{Empowerment}

When a person or a group of people is empowered, they obtain the authority for or possibility of taking part in a process (also of decision-making)/taking up a role that is important for them, but was previously inaccessible. Empowerment can be active (i.e. by means of direct participation) or passive (i.e. by changing political, economic or social conditions).

\section{Enabler}

Enablers, or "enabling conditions," are the counterparts of challenges. They make it possible (or easier) for a project to be executed. Enabling conditions may happen to be present for a project, e.g. favourable circumstances or advantageous particularities of the (composition of the) team. However, they can also be actively introduced, for example by using tools, strategies or techniques for organising and/or implementing a project.

\section{Ethical}

Generally speaking, ethics is the study of systems of norms, principles and values that demarcate the morally good. An action is ethical when it is motivated by reasons that adhere to an ethical system (i.e. when an intentionalist perspective is adopted) and/or when its effects are in line with an ethical system (i.e. when a consequentionalist perspective is adopted). In urban research and practice, this 
often comes down to respecting relevant ethical systems and sensitivities and/or creating a positive impact on people's lives and the environment.

\section{Facilitation}

Facilitation is understood as a core competence for integrating knowledge in an inter- and transdisciplinary process. Further, it is seen as a means to reach the goal of co-producing knowledge among various actors with diverse interests and agendas.

\section{Innovation}

Innovation stands for the introduction of a novelty that, in many cases, once fully implemented, will generate more changes. The introduced novelty can be new knowledge (e.g. on material engineering, sociology, sustainability), new methods and techniques (e.g. urban research and practice processes), or it can be a new product (e.g. a new circulation plan, enterprises). It should be noted that, generally, things are only innovative in specific respects or in specific contexts.

\section{Integration}

Cross-disciplinary integration is the process of combining elements from a discipline (e.g. values, methods, information, tools, data, criteria, theories, perspectives, concepts, etc.) with elements from another academic or non-academic discipline. Integration leads to the redefining, re-contextualising or enriching of existing disciplinary elements, or the creation of new elements.

\section{Interdisciplinarity - inspired by Klein (2014)}

Interdisciplinarity is a type of cross-disciplinarity that involves the integration of knowledge from different academic disciplines.

\section{Interprofessionality}

Interprofessionality is the non-academic counterpart of interdisciplinarity. It involves the integration of knowledge from different professions and practices.

\section{Intervention}

An intervention is a targeted change that is made to obtain information and/or to improve a situation. Interventions aimed at obtaining information can be direct (e.g. when they consist of manipulating a system and measuring the effects) or indirect (e.g. when they are set up to bring people together who are then requested to provide information). Ideally, interventions that aim at making improvements are supported by research.

\section{Intradisciplinarity}

When researchers with a shared disciplinary background collectively reflect on their training and practice in order to gain insight into (different schools within) the discipline, to define a discipline and/or to determine future goals of their discipline, their efforts can be labelled as "intradiscipli- 
nary." Given a broad interpretation of "discipline" (i.e. as an "area of expertise"), "intradisciplinarity" can also refer to the self-reflective practice of professionals and practitioners.

\section{Knowledge}

Knowledge is insight into or understanding of a certain subject or phenomenon (which can be scientific, aesthetic or ethical). Knowledge can be explicit or tacit, theoretical or practical.

\section{Knowledge production}

"Knowledge production" refers to the process of generating new knowledge. When an inter- or transdisciplinary approach is taken, knowledge production is a collective endeavour that involves the integration of input from very different sources and the finding of appropriate (often novel) methods to reach the knowledge goal.

\section{Multidisciplinarity - inspired by Holbrook (2013)}

Multidisciplinarity is a type of cross-disciplinarity that involves the juxtaposition of disciplines (instead of integration, as is the case in inter- and transdisciplinarity); different disciplines synchronically address complementary questions on a subject. Multidisciplinarity enables cross-fertilisation between disciplines.

\section{Network}

A network is a group of entities (e.g. people, institutions, organisations or companies) that is structured around a certain goal or interest. Generally, entities join a network because it grants them access to information and resources. Networks do not necessarily dispose of operating resources, and its members are not necessarily in direct contact.

\section{Participation}

In its simplest form, "participation" refers to taking part or getting involved. In the context of transdisciplinarity, the concept has a strong emancipatory connotation and refers to situations in which people or groups that were initially excluded obtain the opportunity to take part in a project that will affect their living conditions. Because the initial exclusion of such people and groups is generally related to isolation, limited financial means or limited mobility, achieving participation requires a significant effort.

\section{Practitioner}

A practitioner is a person whose occupation is non-academic and involves the application of theoretical knowledge (generally acquired via university education) and/or skills that are specific to a given area of expertise. Being a practitioner does not exclude being an academic. 


\section{Professional}

To be a professional means that one's occupation is non-academic and involves the application of practical and tacit knowledge. Generally, one is only considered to be a professional after having acquired a certain level of experience.

\section{Project}

A project is a unit of knowledge production that is characterised by one or more goals, i.e. certain answers/solutions to the central questions/problems or even a physical resolution. Projects are carried out by teams and their duration is often determined by funding. When a project is inter- or transdisciplinary, it spans co-design, co-production and dissemination phases, and the members of the team responsible have different backgrounds.

\section{Researcher}

In a broad sense, a researcher is someone who studies a subject to learn more about it. In the strict sense, a researcher is someone who is associated with a university or a research institute and is focused on acquiring knowledge (as opposed to applying knowledge).

\section{Resilient}

Like sustainability, the notion of resilience stands for the capacity of surviving, maintaining or continuing. However, while the former draws attention to (the presence of) factors that contribute to this continuation, the latter draws attention to (the withstanding of) factors that threaten continuation.

\section{Stakeholder}

In the context of a project, the stakeholders are the entities (e.g. people, institutions, organisations or companies) that have an interest in the project. "Stakeholder" is most commonly used to refer to the funders of the project as well as to the businesses, associations, federations, policymakers, legislators, etc. who are supposed to benefit from the project.

\section{Sustainable - based on World Commission on Environment and Development (1987)}

Generally speaking, something is sustainable when it is capable of surviving, maintaining or continuing with minimal external input. The term "sustainable" expresses the idea that something meets a set of desiderata that is relevant at a certain time $t$, but that it also meets the desiderata that become relevant at a later point in time $t$. The adjective can be used in a normative manner, i.e. to say that something should be sustainable, or in a descriptive manner, i.e. when stating that something is sustainable. When used normatively, the initial desiderata are situated in the present; when used descriptively, the initial desiderata are situated in the past. In urban contexts, the desiderata relate to living, working and/or moving in an urban environment. 


\section{Transdisciplinarity}

Transdisciplinarity is a type of cross-disciplinarity that involves the integration of academic disciplinary knowledge with knowledge, values and interests from professionals, practitioners, decisionmakers and/or stakeholders.

\section{Transferable knowledge - inspired by Kirkeby (2011)}

Transferable knowledge is knowledge that is generated in the context of a given project and/or for a specific purpose, but that is applicable to other projects and/or purposes, given that the novel context shows certain (structural) resemblances to the original one.

\section{Transformative}

The notion of transformation is closely related to those of novelty and preservation, as it refers to existing things being changed (profoundly) rather than to entirely new things being created. Possible subjects of transformation are theoretical (e.g. scientific knowledge), organisational (e.g. education, research, politics or economics) or physical (e.g. infrastructure).

\section{Trust}

Trust in an entity is a necessary condition to be able to outsource a certain task or responsibility to that entity without major worries or concerns. Building trust can take a lot of time because the trusting party needs to ascertain that the trusted party is not likely to abuse the power that comes with responsibility.

\section{Urban}

"Urban" is the antonym of "rural" and refers to (the organisation of) life, housing, transport, planning, heritage, the environment and public space in cities and other densely populated areas.

\section{References}

Bourdieu, P. (1999). Outline of the theory of practice. Cambridge: Cambridge University Press.

Eigenbrode, S.D., O’Rourke, M., Wulfhorst, J. D., Althoff, D. M., Goldberg, C. S., Merrill, K. \& BosquePérez, N. A. (2007). Employing philosophical dialogue in collaborative science. BioScience, 57(1), 55-64.

Holbrook, J.B. (2013). What is interdisciplinary communication? Reflections on the very idea of disciplinary integration. Synthese, 190(11), 1865-1879.

Kirkeby, I.M. (2011). Transferable knowledge - an interview with Bent Flyvbjerg. Architectural Research Quarterly, 15(1), 9-14.

Klein, J.T. (2014). Interdisciplinarity and transdisciplinarity: Keyword meanings for collaboration science and translational medicine. Journal of Translational Medicine \& Epidemiology, 2, 1024-1030.

Klepousniotou, E. (2002). The processing of lexical ambiguity: Homonymy and polysemy in the mental lexicon. Brain and Language, 81(1-3), 205-223.

Lang, D.J., Wiek, A., Bergmann, M., Stauffacher, M., Martens, P., Moll, P., Swilling, M., \& Thomas, C.J. (2012). Transdisciplinary research in sustainability science: Practice, principles, and challenges. Sustainability Science, 7(1), 25-43. 
Mauser, W., Klepper, G., Rice, M., Schmalzbauer, B.S., Hackmann, H., Leemans, R., \& Moore, H. (2013). Transdisciplinary global change research: The co-creation of knowledge for sustainability. Current Opinion in Environmental Sustainability, 5(3-4), 420-431.

Nikulina, V., Larson Lindal, J., Baumann, H., Simon, D., \& Ny, H. (2019). Lost in translation: A framework for analysing complexity of co-production settings in relation to epistemic communities, linguistic diversities and culture. Futures, 113, 102442, https://doi.org/10.1016/j.futures.2019.102442.

O'Rourke, M., \& Crowley, S.J. (2013). Philosophical intervention and cross-disciplinary science: The story of the Toolbox Project. Synthese, 190(11), 1937-1954.

Polk, M. (2015). Transdisciplinary co-production: Designing and testing a transdisciplinary research framework for societal problem solving. Futures, 65, 110-122.

Putnam, R.D. (1993). What makes democracy work? National Civic Review, 82(2), 101-107.

Szostak, R. (2014). Communicating complex concepts. In: O’Rourke et al. (Eds.), Enhancing communication \& collaboration in interdisciplinary research, pp. 34-55. Thousand Oaks, CA: Sage Publications.

Tuggy, D. (1993). Ambiguity, polysemy, and vagueness. Cognitive Linguistics (includes Cognitive Linguistic Bibliography), 4(3), 273-290.

von Wehrden, H., Guimarães, M-H., Bina, O., Varanda, M., Lang, D-J., John, B., Gralla, F., Alexander, D., Lawrence, R-J., Raines, D., \& White, A. (2018). Interdisciplinary and transdisciplinary research: Finding the common ground of multi-faceted concepts. Sustainability Science, https://doi.org/10.1007/s11625018-0594-x.

Wear, D.N. (1999). Challenges to interdisciplinary discourse. Ecosystems, 2(4), 299-301.

World Commission on Environment and Development. (1987). Our common future: report of the world commission on environment and development. Oxford: Oxford University Press. 